\title{
Quality assurance in reading radiographs for pneumoconiosis: AIR Pneumo program
}

Naw Awn J-P M.D., Ph.D.

Narufumi Suganuma M.D., Ph.D.

From Department of Environmental Medicine, Kochi Medical School, Kochi University, Nankoku, Kochi, Japan.

Address correspondence to N.A. (e-mail: jpnawawn@kochi-u.ac.jp)

Conflict of Interest: The authors declare that they have no conflict of interest.

Keywords: Chest radiography, ILO classification system, Pneumoconiosis, Quality assurance, AIR Pneumo.

\section{Background}

Occupational exposures to various dusts are widespread and pneumoconiosis represents one of the major occupational lung diseases worldwide. Chest radiography is extensively used in the screening for pneumoconiosis in dustexposed workers. However, recognition of early pneumoconiosis in a chest radiograph is difficult and interpretation is different among physicians. To achieve uniformity in interpretation, the International Labour Office has developed a standardized system for reading chest radiographs for the presence of pneumoconiosis (ILO Classification system) [1]. Despite the introduction of this classification system, inconsistency between readings exists among physicians as well as an individual physician. To improve consistency in readings and to 
maintain physicians' proficiency in using the ILO Classification system, the National Institute for Occupational Safety and Health (NIOSH) of the United States has developed the B Reader Certification Program in 1974 [2]. This program provides training courses in the application of the ILO Classification system and administers examinations for certification. The B Reader Certification Program also opens to physicians from outside the United States; however, most physicians from developing countries have several constraints in accessing the benefits offered by the program.

\section{Asian Intensive Reader of Pneumoconiosis (AIR Pneumo)}

Back in 2003, a dialogue was developed between a government official of Thailand and Professor Yukinori Kusaka (School of Medicine, University of Fukui, Japan) about setting up an Asian certification program for reading chest radiographs for pneumoconiosis. Following this, a number of experts, all having backgrounds within occupational medicine, formed a working group, used their expertise to formulate the structure of the program. The team consisted of experts from across the world including Brazil, China, Germany, India, Japan, Thailand, the United States, and Viet Nam. During a series of workshops, the expert group made a great effort to develop a comprehensive training course and an examination program. Finally, in 2006, the Asian Intensive Reader of Pneumoconiosis (AIR Pneumo) (www.airp.umin.jp) was established as an academia-based quality assurance program for physicians' proficiency in reading chest radiographs for pneumoconiosis [3]. The objective was to upgrade the skills of physicians in developing Asian countries in reading chest radiographs for pneumoconiosis by using the ILO Classification system.

To fulfill its objective, AIR Pneumo provides a program involving training, examination, and certification to all physicians who are working to protect workers' health. AIR Pneumo program is driven by an international expert 
committee. The committee members came from various disciplines including chest medicine, occupational medicine, public health, and radiology. Most importantly, all have the same interests in the prevention of pneumoconiosis. The training courses are designed as two days of lectures and practical exercises using examples chest radiographs [4]. The lectures include the epidemiology of dust-induced lung diseases, basic principles and quality in chest radiography, radiological findings consistent with dust-induced pulmonary and pleural lesions, and the application of the ILO Classification system in screening and surveillance for pneumoconiosis. The practical exercise sessions involve an interactive reading of representative chest radiographs of pulmonary and pleural lesions instructed by international experts. In the examination, candidates classify 60 chest radiographs. Performance in the examination is assessed by the accuracy in detecting parenchymal lesions consistent with pneumoconiosis, accuracy in detecting pleural lesions, and consistency in classifying shape and profusion of small opacities. A participant must pass the examination to receive the AIR Penumo Certification. To maintain their status, they must pass a recertification examination every five years.

\section{ASEAN community countries and pneumoconiosis}

For the first time in 2014, a conference for cooperation among ASEAN community countries to improve the proficiency in reading chest radiographs for pneumoconiosis according to the ILO Classification system was organized in Chiangmai, Thailand. ("ASEAN Conference for the Development of National Readers for ILO Classification" Project of Cooperation among ASEAN Community Countries to improve the diagnosis and proficiency in Reading Pneumoconiosis Chest Radiographs According to ILO Classification, 28-30 July 2014, Chiangmai, Thailand.) Officials from eight ASEAN community countries including Brunei, Cambodia, Indonesia, Laos, Malaysia, the Philippines, Thailand, and Vietnam presented in the conference. The national as well as regional situation in the epidemiology, prevention and control of pneumoconiosis were discussed. The following facts are derived from the conference: 
1. The estimated dust-exposed workers ranged from 40,000 to 1.6 million across the ASEAN countries. The major occupation included construction, coal mining, quarries, stone carving, stone cutting and grinding, foundry, porcelain and ceramics, and sandblasting.

2. The estimated prevalence of pneumoconiosis ranged from $20 \%$ to $40 \%$ of the potential population. However, there were no established reporting and a data management system for pneumoconiosis across ASEAN countries.

3. In 2014, the number of dedicated occupational health physicians ranged from 8 to 500 across ASEAN countries. Generally, the diagnosis of pneumoconiosis is performed by chest physicians; however screening is conducted by occupational health physicians.

4. Only five ASEAN community countries (Indonesia, Malaysia, the Philippines, Thailand, and Vietnam) conducted training workshops (in collaboration with the ILO) to promote physicians' proficiency in the application of the ILO Classification system in the past. Only Thailand has qualified NIOSH B Readers.

5. All ASEAN community countries showed their interests in training national readers for pneumoconiosis.

The conference concluded that fostering physicians who are competent in reading chest radiographs for pneumoconiosis is central to the implementation of proper medical screening, and it is also important to the prevention of pneumoconiosis. The training programs could be organized through regional cooperation among ASEAN community countries along with collaborative supports from international organizations such as the ILO. 


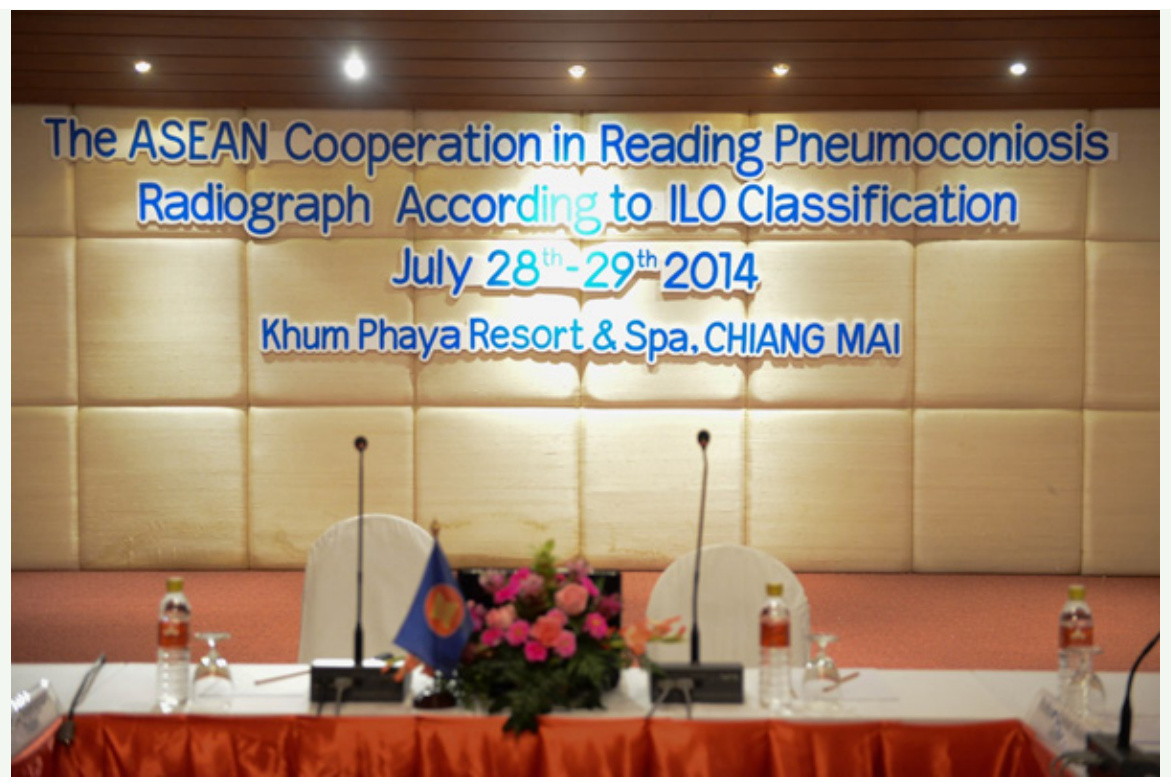

The ASEAN Conference for the Development of National Readers for ILO Classification: Project of Cooperation among ASEAN Community Countries to improve the diagnosis and proficiency in Reading Pneumoconiosis Chest Radiographs According to ILO Classification held in Chiang Mai, Thailand, 28-30 July 2014

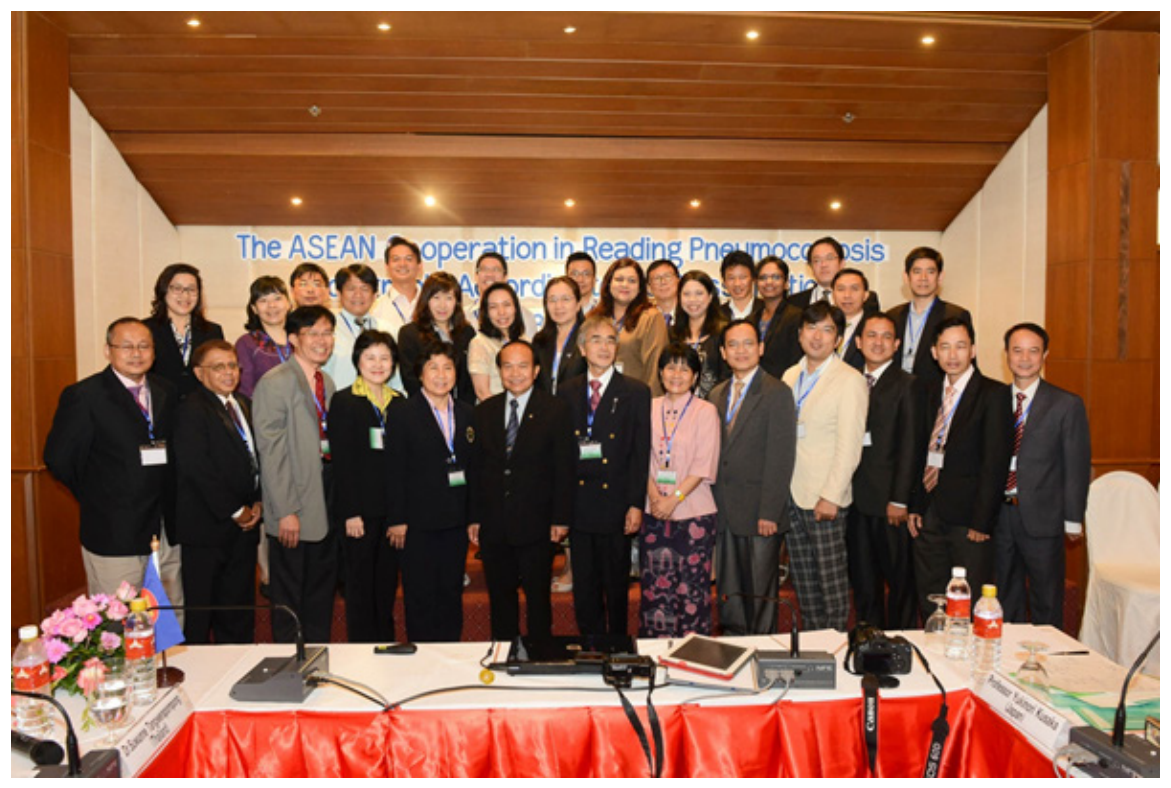

The experts from Japan and the participants from eight ASEAN countries including Brunei, Cambodia, Indonesia, Laos, Malaysia, Philippines, Thailand, and Viet Nam. 


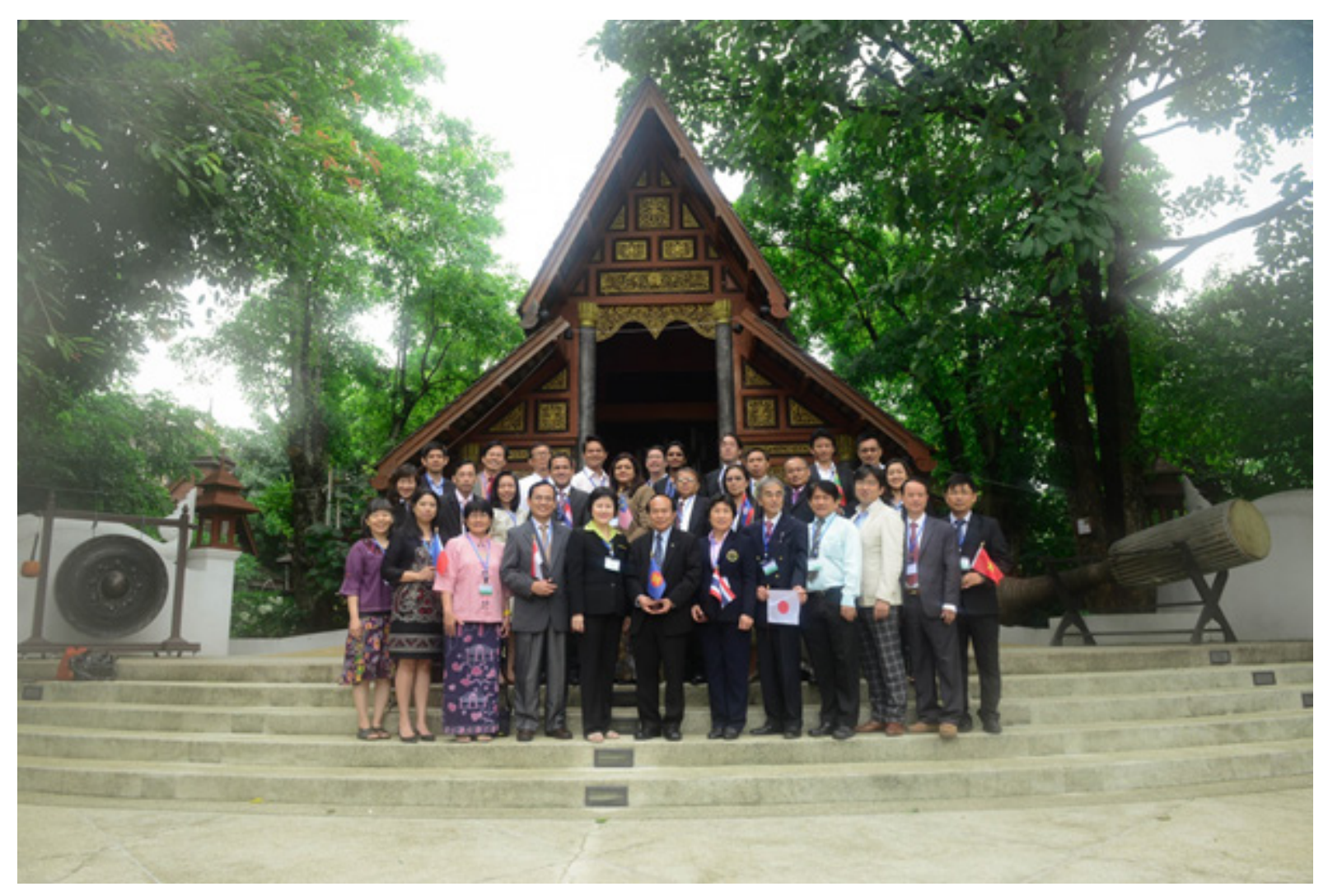

The 1st conference was held in Chiang Mai in Northern Thailand. 


\section{Positioning of AlR Pneumo in pneumoconiosis prevention}

To promote physicians' proficiency in reading chest radiographs for pneumoconiosis in developing Asian countries, the AIR Pneumo is working hard through international collaboration including the Asian Pacific Society of Respirology (APSR), the International Labour Office (ILO), the Scientific Committee on Respiratory Disorders of the International Commission on Occupational Health (ICOH SCRD), the Research Group for Occupational Lung Diseases of the Japan Society for Occupational Health (JSOH), the Research Group for International Cooperation in Occupational Health of the Association of Occupational and Environmental Diseases of Thailand (AOET), the Central Chest Institute of Thailand (CCIT), and the Bureau of Occupational and Environmental Diseases of the Ministry of Public Health of Thailand. Previously, the Central Chest Institute of Thailand was the only institution that could accommodate candidates for the AIR Pneumo training and examination programs. At the Central Chest Institute of Thailand, the program was conducted biennially and physicians from other Asian countries (such as Bhutan, Hongkong, India, Taiwan) participated. From 2018, AIR Pneumo, in collaboration with Universitas Indonesia-Persahabatan Hospital, Universitas Indonesia Hospital Depok, the Indonesian Society of Respirology (ISR) and the Indonesian Occupational Medicine Association, and expanded its training and examination program to Indonesia. Examination seats could be arranged for about forty number of candidates. By the end of 2019, AIR Pneumo has successfully conducted it's training and examination programs twenty two times in several countries: India, the Philippines, and Vietnam hosted once; Indonesia did so thrice, Brazil, and Japan organized it five times in each country, and Thailand held it for six times. The examination for AIR Pneumo certification was administered to 530 candidates, including 138 chest physicians, 150 occupational physicians, and 100 radiologists (see the table). Of the 530 physicians, 425 physicians received certifications for their competency in classifying chest radiographs for the presence of pneumoconiosis. 


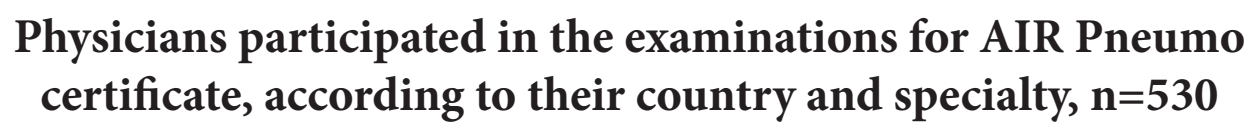

$\begin{array}{lll} & \mathbf{n} & (\%) \\ \text { Country } & & \\ \text { Brazila } & 48 & (9.1) \\ \text { India } & 58 & (10.9) \\ \text { Indonesia } & 140 & (26.4) \\ \text { Japan } & 47 & (8.9) \\ \text { Malaysia } & 15 & (2.8) \\ \text { Philippines } & 23 & (4.3) \\ \text { Thailand } & 128 & (24.2) \\ \text { Viet Nam } & 57 & (10.8) \\ \text { Othersb } & 14 & (2.6) \\ \text { Specialty (n=473) } & & \\ \text { Chest medicine } & 138 & (29.2) \\ \text { General medicine } & 54 & (11.4) \\ \text { Occupational medicine } & 150 & (31.7) \\ \text { Public health } & 22 & (4.7) \\ \text { Radiology } & 100 & (21.1) \\ \text { Others } & 9 & (1.9) \\ \text { AIR Pneumo certified physicians } & 427 & (80.6) \\ \text { physicians from Argentina, Chile, and Peru } & & \\ \text { physicians from Brunei, Cambodia, DR Congo, Hong } & \text { Kong, Khindom of } \\ \text { yanmar, Parkistan, and Taiwan } & & \end{array}$

In 1995, the International Labour Organization and World Health Organization launched a Global Program on the Elimination of Silicosis (WHO/ILO GPES) [5]. The objective was to eliminate new cases of silicosis in all countries by 2030. In order to support the implementation of the ILO/WHO GPES, the AIR Pneumo is active in disseminating knowledge, educating physicians in reading radiographs for pneumoconiosis, and performing as a "special bridge" to promote relations and cooperation among Asian countries. 


\section{Acknowledgments}

AIR Pneumo project consumed great amount of work, research, and dedication. Still, it's training and examination programs would not have been possible without supports from many individuals and organizations. Therefore, we would like to extend our sincere gratitude to all of them, but the list here is not exhaustive. First of all, we are grateful to Yukinori Kusaka (Emeritus Professor, University of Fukui, Japan; Former Chair, AIR Pneumo Project), Hisao Shida (Committee of Compensation of Asbestos-related Diseases, Ministry of the Environment, Japan), Masanori Akira (Department of Radiology, National Hospital Organization Kinki-Chuo Chest Medical Center, Japan), Taro Tamura (Fukui City Public Health Center, Japan), Somkiat Siriruttanapruk (Department of Disease Control, Ministry of Public Health, Thailand), Ponglada Subhannachart (Advisory Level, Central Chest Institute of Thailand), Sutarat Tungsagunwattana, MD (Central Chest Institute of Thailand), Xing Zhang (Zhejiang Academy of Medical Sciences, China), Prahalad K. Sishodiya (National Institute of Miners' Health, India), Tran Anh Thanh (Occupational Health Management Division, Ministry of Health, Viet Nam), Kurt G. Hering (Department of Diagnostic Radiology, Radio-oncology and Nuclear Medicine, Radiological Clinic, Miner's Hospital, Germany), John E. Parker (Pulmonary and Critical Care Medicine, Robert C. Byrd Health Sciences Center, School of Medicine, West Virginia University, USA), Eduardo Algranti (Divisao de Medicina, Fundacentro, Brazil), Agus Dwi Susanto (Department of Pulmonology and Respiratory Medicine, Faculty of Medicine, Universitas Indonesia), Muchtaruddin Mansyur (Occupational Medicine Division, Faculty of Medicine, Universitas Indonesia) for provision of expertise, and technical support to the project. Second, we would like to express our sincere thanks towards volunteer experts who devoted their time and knowledge in the training programs as lecturers. Finally, we express our gratitude toward all the participants of the AIR Pneumo training and examination programs. 


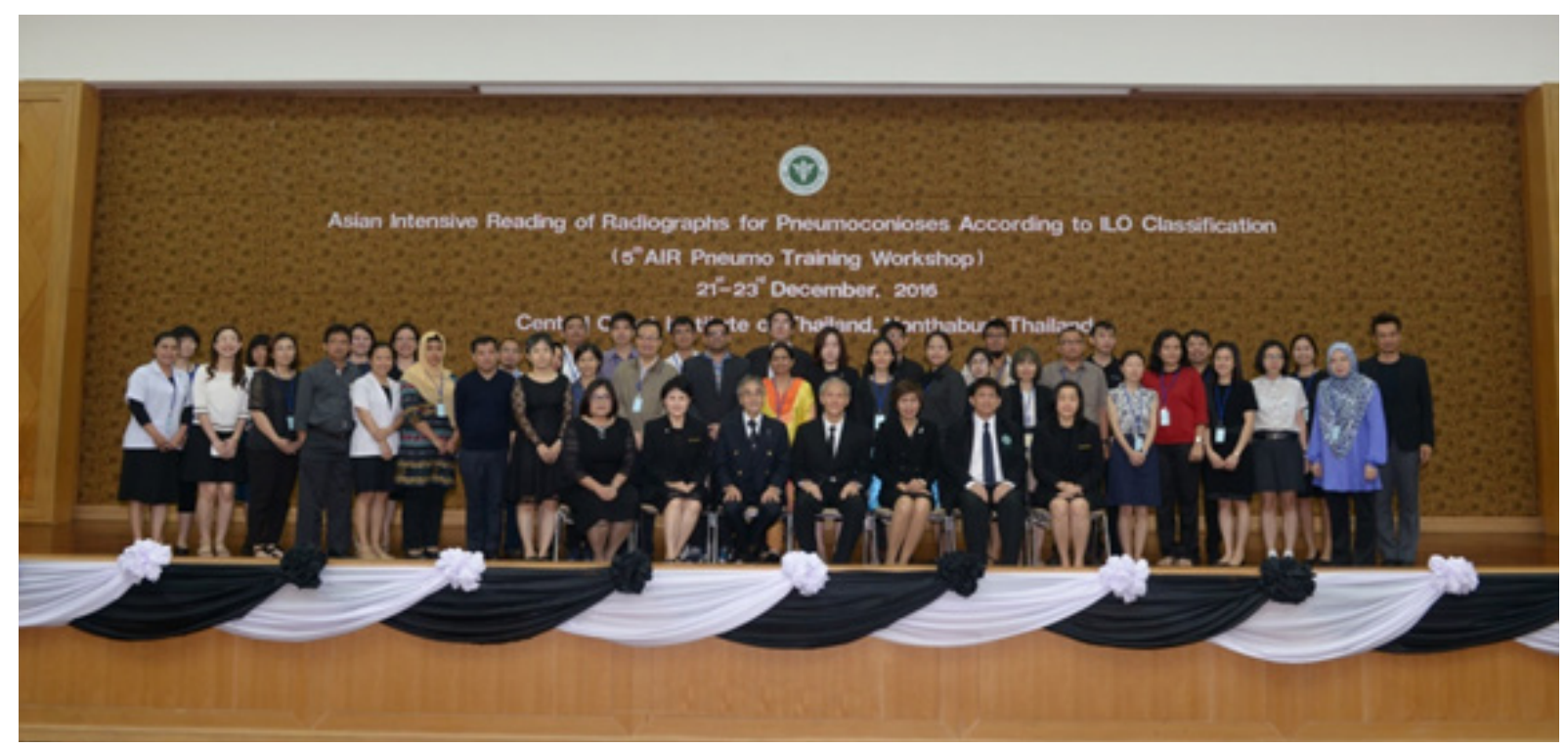

Speakers and participants in the $5^{\text {th }}$ AIR Pneumo Training Workshop in Thailand held in December 2016

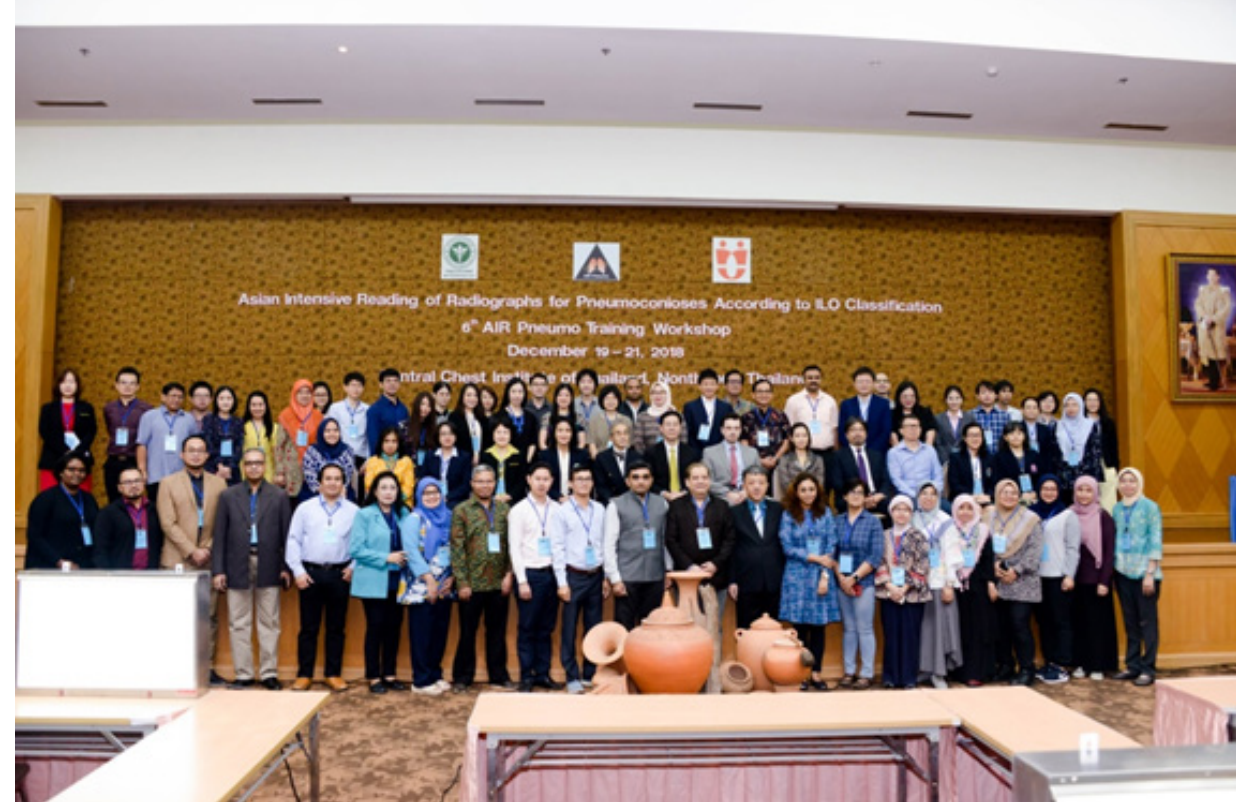

Expansion of the project. More participants joining the $6^{\text {th }}$ AIR Pneumo Training Workshop at Central Chest Institute of Thailand in December 2018 


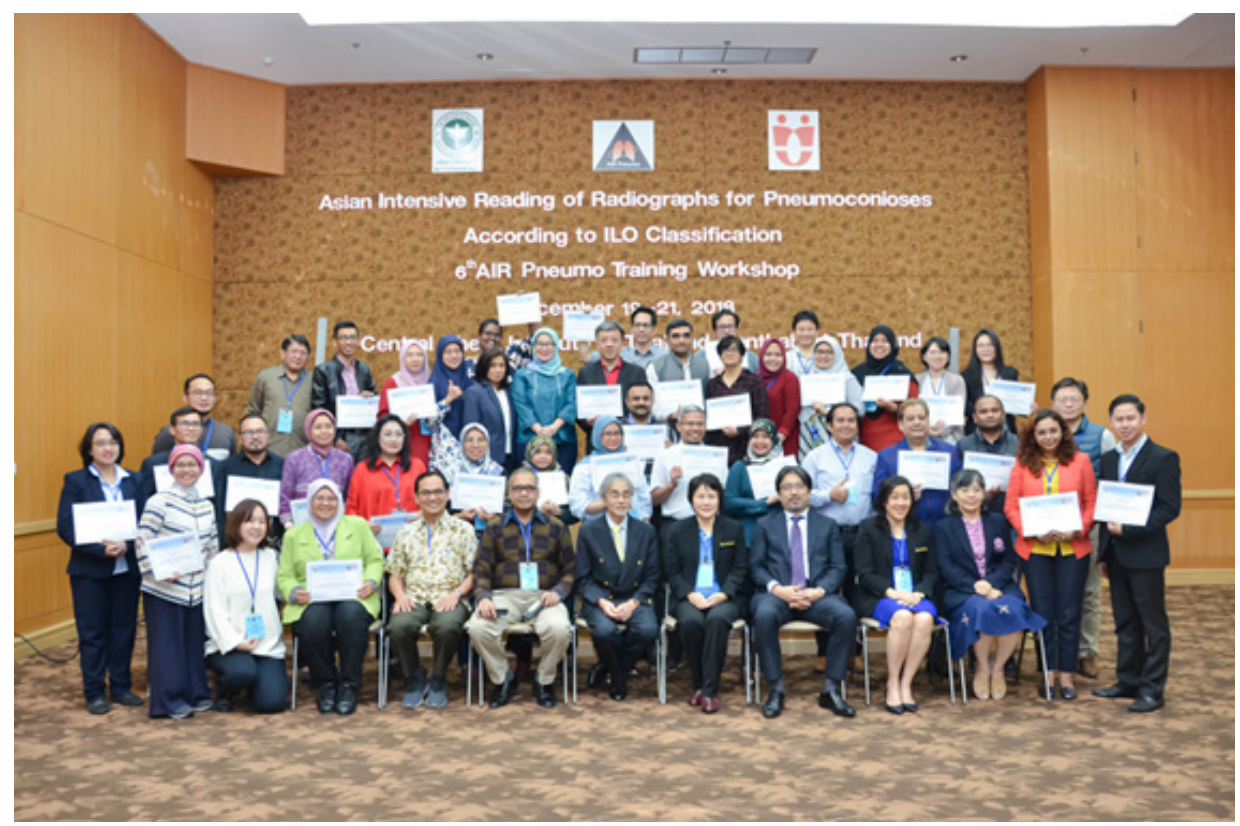

Closing ceremony and certificate presentation to the successful participants at the $6^{\text {th }}$ and the latest AIR Pneumo Training Workshop in December 2018

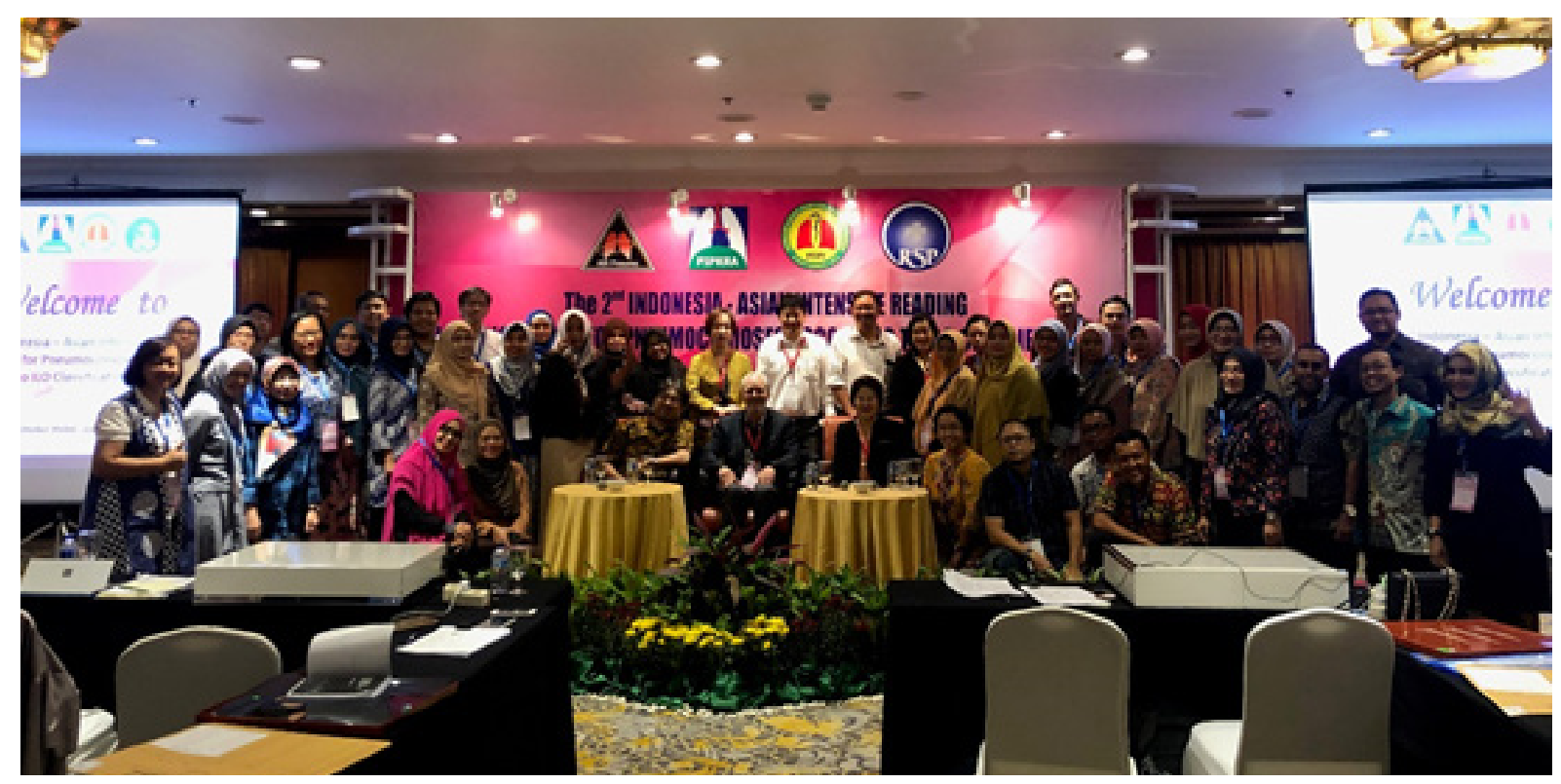

Expansion of the project. The 2nd AIR Pneumo Training Workshop in Indonesia held in February 2019 


\section{References}

1. International Labour Office. Guidelines for the use of the ILO International Classification of Radiographs of Pneumoconioses. Revised Edition 2000. Geneva: ILO; 2002.

2. CDC Centers for Disease Control and Prevention [Internet]. Atlanta, GA: The National Institute for Occupational Safety and Health; [updated 2019 March 4; cited 2019 November 15]. Chest Radiography: The NIOSH B Reader Program. Available from: https://www.cdc.gov/niosh/topics/chestradiography /breader.html.

3. Suganuma N, Natori Y, Kurosawa H, Nakano M, Kasai T, Morimoto Y, et al. Update of occupational lung disease. J Occup Health 2019;61:10-8.

4. Zhou H, Kusaka Y, Tamura T, Suganuma N, Subhannachart P, Siriruttanapruk $\mathrm{S}$, et al. The 60 -film set with 8-index for examining physicians' proficiency in reading pneumoconiosis chest X-rays. Ind Health 2012;50:84-94.

5. Fedotov IA, Eijkemans GJM. The ILO/WHO Global Programme for the Elimination of Silicosis (GPES). GOHNET Newsletter 2007;(12):1-3. 